\title{
Detection and Control of Radon and its Progenies in a Tunnel
}

\author{
Hanyuan Mao, Min Zhu, Fei Wu and Huang Huang \\ College of Nuclear Science and Technology, Naval University of Engineering, Wuhan, 430033, China
}

\begin{abstract}
The presence of radon and its progenies in the tunnel directly affects the health of the staff. Effective measures should be taken to lower the concentration of radon and its progenies in the tunnel to reduce their harm to the human body. The article first introduces the investigation results of radon and its progenies in a tunnel, analyzes the monitoring data briefly, and then analyzes the application of ventilation, shielding and adsorption three kinds of methods in the control of tunnel radon, and gives some reasonable advice.
\end{abstract}

\section{1 introduction}

In the standard state, radon $\left({ }^{222} \mathrm{Rn}\right)$ is a kind of colorless and odorless gas. The internal irradiation after inhalation of radon and its progenies is mainly caused by short-lived daughters[1]. The tunnel structure of a national defense fortification is granite geological structure. At the same time, concrete is widely used in the construction. The radon precipitation rate of these two materials is relatively high, so the decantation rate of the whole tunnel is also high. In order to clarify the concentration level of radon in the tunnel, reduce the physical and psychological harm of the substances, and ensure the health of the staff, a survey is conducted on the concentration of radon and its progenies.

\section{Investigation on the level of radon in a tunnel}

\subsection{Detector selection}

The KDY-I radon continuous monitor is selected for the investigation of radon in the tunnel, which is a new type of passive fast radon monitor, widely used in the measurement of radon concentration in residential and underground buildings. Based on the passive diffusion principle, the pump is used to pump air into the detector chamber. The radon in the air decays into its daughters in the chamber and the latter are adsorbed by filtration membranes under the Coulomb force. Then the detector measures the radon concentration via the characteristic decay energy of the alpha particle emitted by the daughters $\left({ }^{218} \mathrm{Po},{ }^{214} \mathrm{Po}\right)$.

The KDY-I radon continuous monitor is used continuously to measure the main working rooms of the tunnel for 24 hours. The air intake port needs to be $75 \mathrm{~cm}$ above the ground to avoid getting close to the wall and ventilation.

\subsection{Monitor condition}

In this survey, eight working rooms in the tunnel are selected as measurement points. Choosing the working rooms in the tunnel as monitoring points is not only for facilitating comparison with previous data, but also fully considered the relatively long time of personnel staying, and it is more practical to investigate the level of radon. During the measurement, the ventilation conditions in the 8 working rooms are as follows:

(1) In the first set of measurements, the working chambers 1 to 8 are turned on for $24 \mathrm{~h}$, and the indoor radon concentration level is measured in a ventilated state.

(2) In order to understand the influence of ventilation on the concentration level of the tunnel radon, in the second set of measurements, after closing the ventilation system of the working room 8 for $24 \mathrm{~h}$, the ventilation system is re-opened, and the concentration of radon in the project is measured after a period of time.

\subsection{Results of monitoring}

Table 1 records the radon levels of the main work spaces for a certain period time in the tunnel in the first set of measurements. During the investigation, it is found that in the case of ventilation, the concentrations of radon in each main working room range from $153 \mathrm{~Bq} \cdot \mathrm{m}^{-3}$ to 671.5 $\mathrm{Bq} \cdot \mathrm{m}^{-3}$, with an average of $326.3 \mathrm{~Bq} \cdot \mathrm{m}^{-3} \cdot 12.5 \%$ of the working room exceed GJB1353-1992 "Nuclear Missile Tunnel Radiation Protection and Its Daughter Radiation Protection" in the first type of tunnel, in which case the concentration limit of radon is $500 \mathrm{~Bq} \cdot \mathrm{m}^{-3}[2] .25 \%$ of the working chamber radon concentration exceeds GB16356-1996 "Underground construction and its annual average action level of the equilibrium equivalent radon concentration" of $400 \mathrm{~Bq} \cdot \mathrm{m}^{-3}$ in the sub-body control standard[3]. Among the 8 measurement locations,

\footnotetext{
*Corresponding author's email: lcmaohanyuan@163.com
} 
there are 6 positions in the range of $200 \sim 500 \mathrm{~Bq} \cdot \mathrm{m}^{-3}$, accounting for $75 \%$, and one place exceeds $500 \mathrm{~Bq} \cdot \mathrm{m}^{-3}$, accounting for $12.5 \%$. The concentration of $\alpha$-potential of radon progenies is $0.74 \sim 1.78 \mu \mathrm{J} \cdot \mathrm{m}^{-3}$, which has certain difference from the control value of radon concentration of $5.4 \mu \mathrm{J} \cdot \mathrm{m}^{-3}$ in air.

Table 1. Radon level of the main working rooms in the tunnel

\begin{tabular}{ccc}
\hline number & $\begin{array}{c}\text { concentration of } \alpha \text {-potential of radon progenies } \\
\left(\mu \mathrm{J} \cdot \mathrm{m}^{-3}\right)\end{array}$ & $\begin{array}{c}\text { Concentration of radon } \\
\left(\mathrm{Bq} \cdot \mathrm{m}^{-3}\right)\end{array}$ \\
\hline 1 & $1.16 \pm 0.39$ & $312.3 \pm 48.6$ \\
2 & $1.63 \pm 1.14$ & $587.3 \pm 116.4$ \\
3 & $1.34 \pm 0.62$ & $378.5 \pm 67.3$ \\
4 & $1.52 \pm 0.59$ & $435.3 \pm 65.8$ \\
5 & $1.09 \pm 0.35$ & $228.3 \pm 45.7$ \\
6 & $1.39 \pm 0.58$ & $395.3 \pm 64.2$ \\
7 & $1.27 \pm 0.37$ & $351.3 \pm 47.8$ \\
8 & $1.92 \pm 0.18$ & $176.7 \pm 23.7$ \\
\hline
\end{tabular}

The data in table 1 indicates that the concentrations of radon in the main working area in the tunnel are relatively high, which is related to the structural characteristics, geological conditions, locations and ventilation of the area. In general, areas with independent ventilation ducts and good ventilation will have relatively low concentration of radon, even close to the indoor radon concentration limit of $200 \mathrm{~Bq} \cdot \mathrm{m}^{-3}$; With the working area farther away from the ventilator, the radon concentration gradually becomes high, and after ventilating for some time, the concentration of radon decreases not so clear. In addition, during the monitoring period, the amount of radon in the water of the cave also increase, which can also explain the high concentration of radon in each working room in some extent.

\section{Control methods for radon and its progenies}

At present, there are mainly three methods for controlling the concentration of radon and its progenies in the tunnel, namely, ventilation, shielding, and adsorption[4], in which circulating ventilation with outside space is the most effective, and this method is mainly used for the tunnel in this investigation.

\subsection{Ventilation}

In general, there are four effects in decreasing the radon level via ventilation[5]: exclusion, dilution, inhibition, and sedimentation. There are three main types of exhaust ventilation: press-in ventilation, extraction ventilation, and combined ventilation. At present, the ventilation of the tunnel is mainly realized by press-in ventilation. The advantage of press-in ventilation is that it maintains a high positive pressure on the inlet ducts, and the external seepage caused by the difference of internal and external pressure in the surrounding rock is conducive to suppress the precipitation of radon.

The flow of circulating ventilation directly affects the concentration of radon. The greater the flow is, the faster the concentration of radon in the tunnel area decreases. Assuming that the concentration of radon in the atmosphere is zero, then the intrusion pollution is zero. Under stable ventilation conditions, the relationship between radon and its progenies' concentration mainly depends on the ventilation time. The relationship between the radon concentration $C_{t}$ in the volume $V$ during time $t$ and the ventilation rate and the ventilation time $t$ can be expressed by equation (1):

$$
C_{t}=\frac{R}{\lambda V+Q}+\left[C_{0}-\frac{R}{\lambda V+Q}\right] e^{-t}\left(\lambda+\frac{Q}{V}\right)
$$

Where $C_{t}$ is the radon concentration at time $t, \mathrm{~Bq} \cdot \mathrm{m}^{-3}$; $C_{0}$ is the radon concentration at the initial moment, $\mathrm{Bq} \cdot \mathrm{m}^{-3} ; R$ is the radon gas release rate in the ventilation space, $\mathrm{Bq} \cdot \mathrm{min}^{-1} ; Q$ is the ventilation rate of fresh air supplied to the ventilation space, $\mathrm{m}^{3} \cdot \mathrm{min}^{-1} ; \lambda$ is the decay constant of radon, $\mathrm{min}^{-1} ; V$ is the ventilation volume, $\mathrm{m}^{3}$.

It can be seen from equation (1) that when $t$ increases, $C_{t}$ begins to decrease, and when $t$ increases to a large value, the second term in the right of the equation will be very small, then the concentration of radon is mainly depend on the first term, which means when the $V$ and $Q$ are specified, and the concentration of radon reduced to a lower level, there is no need to increase the ventilation time, therefore the ventilation time of the tunnel is not the longer the better[6].

Table 2 is the results of the second set of measurement, which is a series of measured radon concentration data after the ventilation system of the working room 8 is closed for 24 hours.

It can be seen from the data in table 2 that the concentration of radon does not decrease within half an hour after ventilation, but rises slightly. It's considered that the value increase is caused by the use of bulging ventilation, and there is a certain accumulation of radon in the ducts being sent in the process. Then the concentration is reduced after one hour of ventilation. This is because the fresh air replenished gradually dilutes the radon in the workplace. After continuing ventilating, the concentration of radon gradually decreases. After two hours of ventilation, the concentration of radon no longer significantly decreases, which is based on the second term in equation (1) gradually approaching zero. After the ventilation is stopped, the concentration of radon will 
hold in a low level for a moment, then it will gradually increase due to the diffusion of air. when the ventilation is stopped for 1 hour, the radon concentration is close to the level before the ventilation.

Table 2. Radon level before and after ventilation in the workplace

\begin{tabular}{cc}
\hline time & $\begin{array}{c}\text { Concentration of radon } \\
(\mathrm{Bq} / \mathrm{m} 3)\end{array}$ \\
\hline Half hour before ventilation & 316.8 \\
Begin ventilation & 338.2 \\
Half hour after ventilation & 354.1 \\
One hour after ventilation & 271.6 \\
One and half hour after ventilation & 189.5 \\
Two hour after ventilation & 176.8 \\
Stop ventilation & 183.2 \\
Half hour after stop & 237.3 \\
One hour after stop & 289.4 \\
\hline
\end{tabular}

\section{2 shielding}

The radon in the tunnel is produced by the decay of nuclides such as uranium and radium in the mountain. It mainly moves through the pores of the rock by diffusion and convection. It continuously enters the atmosphere inside the tunnel via the capillary of the coating layer, and is concentrated between the mountains and walls. If a closed-cell material with a suitable thickness and a small diffusion coefficient is sprayed on the surface of the coating layer, connecting the shielding layer to the covered layer and integrating them into one, then it is equivalent to reducing the porosity of the coating layer and increasing the gas diffusion resistance, and achieve the purpose of decrease the level of radon[7].

At present, the specific method for tunnels is to paint regularly. Theoretically, the coating can also reduce the pores and increase the diffusion resistance of the radon gas, which has good effect on the shielding of radon, but because it is not a professional anti-mite coating, the actual effect needs to be further verified.

\section{Conclusion}

The radon and its progenies exist everywhere in the tunnel. Working in such places for a long time can be harmful to the health of the staff. Understanding the hazards of radon and its progenies actively, detecting and controlling radon and its progenies in tunnel work are of great significance to safeguarding the health of workers. In this paper, according to the special geological conditions dominated by granite in a certain tunnel, the main concrete structure and the actual situation of each warehouse, the control methods of the radon and its progenies in the tunnel area is discussed.

\section{Reference:}

1. Qiuju Guo, Shouyuan Xu. (2004) Hazard and dose estimation of radon[J]. Chinese Journal of Radiological Medicine and Protection. 24(1): 85-87.

2. GJB1353-1992, Nuclear Missile Tunnel Radiation
Protection and Its Daughter Radiation Protection, [S].

3. GB16356-1996, Underground construction and its annual average action level of the equilibrium equivalent radon concentration [S].

4. Wei Qi, Shibin Geng, Hushan Gao, et al. (2011) The Research Status and Application of Radon Reduction Technology in Defense Projects[J]. Contamination Control \& Air-Conditioning Technology. 01: 40-42.

5. Zheng Liang, et al. (2006) Ventilation and radon reduction in uranium mine $[\mathrm{J}]$. Journal of Safety Science and Technology, 02(1): 53-56.

6. Longfei $\mathrm{Hu}$, Guodong Zhao, Penghua $\mathrm{Hu}$, et al. (2018) Present Situation, Problems and Countermeasures of Radon Reduction in Uranium Mine Well in China[J]. Uranium Mining and Metallurgy., 01: 55-57.

7. Lijun Wang, Jianwei Gong, et al. (2005) Radon Hazard in the Dwelling and Corresponding Precautionary Measures. Contamination Control \& Air-conditioning Technology. 04: 66-68. 